\title{
Morphological Analysis on Electric Vehicles' Operating Model: Cases of Beijing Taxi Area
}

\author{
Suxiu $\mathrm{Li}^{1}$, Xingtong Chen ${ }^{1}$ and Zeyuan Song ${ }^{2, *}$
}

\author{
${ }^{1}$ Energy Internet Research Centre, State Grid Energy Research Institute \\ ${ }^{2}$ School of Economic and Management, Beijing Jiaotong University \\ *Corresponding author.Email: lisuxiu@163.com
}

\begin{abstract}
Since the launch of the "Ten Cities, One Thousand Vehicles" demonstration project in 2009, the application and promotion of electric vehicles in China has been effective, especially in the field of public transport, where electric vehicles have gradually become an important part of public transport operations. The article examines the operation mode of electric taxis in Beijing on the basis of a review of the promotion status and operation mode of electric taxis in China. Combining previous research and industrial practice, the article constructs a morphological matrix analysis framework for the electric vehicle operation mode from a systematic perspective, covering the elements involved in the three aspects of vehicle and battery, charging infrastructure and system services, and by integrating the three aspects, it forms a systematic framework for analysing the electric vehicle operation mode; on the basis of the theoretical construction, the article selects the Beijing electric taxi as a case study and applies the On the basis of the theoretical construction, the article selects Beijing electric taxis as a case study and applies the theoretical framework to analyse each of the elements involved in Beijing electric taxis and discusses their characteristics and shortcomings, thus providing suggestions for future promotion and innovation. The study shows that the operation model of electric taxis in Beijing still suffers from inadequate charging infrastructure, a single overall profit model, lack of diversification and intelligence of system services, and dependence on subsidies. Therefore, the article argues that there is a need to consider the whole promotion and operation model from a systemic thinking, especially to change the operation mode and profit model of charging infrastructure and system services, to improve the profitability of the whole operation system, and to promote the development and promotion of electric taxis in the urban transportation system.
\end{abstract}

Keywords: Electric vehicle industry, Electric taxi, Operating model, Morphology matrix, Beijing case.

\section{INTRODUCTION}

Since 2009, when the Ministry of Science and Technology, the Ministry of Finance, the National Development and Reform Commission, the Ministry of Industry and Information Technology and other ministries and commissions jointly released the "Ten Cities and Thousands of Vehicles" energy-saving and new energy vehicles demonstration and application project, the application and promotion of electric vehicles in China has gradually become effective. In Beijing, Shenzhen, Hangzhou and Wuhan, electric taxis have gradually taken up a certain proportion of the fleet, and have formed business models with local characteristics, such as the Hangzhou power exchange model and the Shenzhen fast-charging model, providing a good demonstration effect for the promotion and application of electric taxis in other cities.

In terms of academic research, there are currently four main areas of research at home and abroad: vehicles and batteries, charging infrastructure, system services, and a comprehensive study of the above three levels. The vehicle and battery aspects include the Hefei directional purchase model, the Hangzhou microbus model and the Shenzhen Putian model [1-4]. The charging infrastructure involves the V2G (Vehicle-togrid) and V2H (Vehicle-to-home) models, the Sanya Skypump model of wind-powered electric vehicle charging station in Barcelona, and also includes theoretical studies of charging and energy supply models for electric vehicles [5-11]. System services are mainly a study of connected vehicles, involving 
research on models such as the Car2go model for offsite car returns, the Autolib model for shared electric vehicles, and the SoCal electric vehicle model in the US [12-14]. In terms of research on system synthesis, the theoretical constructs of commercial operation model systems have been studied from a systems theory perspective, as represented by the studies of Ye Qiang et al. (2012) and Kley et al. (2011) [15-16].

This paper takes Chinese electric taxis as the main object, uses Kley's morphological matrix analysis framework of electric vehicle operation model as the theoretical basis, constructs a morphological matrix analysis framework of Chinese electric vehicle operation model, and uses Beijing electric taxis as an example to conduct a case study to analyse in depth the basic elements of the three aspects involved in electric taxis, namely the whole vehicle and battery, charging infrastructure and system services, so as to This will help to clarify the important factors influencing the operation mode of electric vehicles and provide corresponding recommendations.

\section{MORPHOLOGICAL MATRIX ANALYSIS FRAMEWORKS FOR ELECTRIC VEHICLE OPERATING MODELS IN CHINA}

Morphological matrix theory was first introduced in the 1940s by the Swedish scholar Dr. Fritz Zwicky. Morphological matrix theory is a theoretical approach based on a comprehensive analysis of the system, using set theory to conceptualise the factors of the project under study. Foreign scholar Kley (2011) innovatively applied the morphological matrix theory method to the analysis of electric vehicle business operation mode [16], and provided a theoretical basis for the analysis of the morphological matrix of electric vehicle business operation mode by incorporating the value positioning, value chain creation and profit model of business model elements, and starting from three perspectives: complete vehicle and battery, charging infrastructure and system service The analysis framework of the morphological matrix for the systematization of foreign electric vehicle operation models was constructed by listing the corresponding operation model characteristics and the functional identifiers of the influencing factors corresponding to each characteristic, and the Better Place case was studied on the basis of this analysis framework. The empirical analysis of the constructed morphological matrix analysis framework of electric vehicle operation model is realized.

This paper cites foreign scholars Kley (2011) and Tukker (2014) on the morphological matrix analysis framework of electric vehicle business models [16,21], combines the characteristics of China's electric vehicle industry, identifies the factors of electric vehicle operation models, arranges them into a matrix diagram, and then analyses the operation models according to the matrix diagram, so as to construct a "morphological matrix analysis framework of electric vehicle operation models in China". The morphological matrix analysis framework of electric vehicle operation mode in China is summarized from three aspects: vehicle and battery, charging infrastructure, and system service, and combined with the actual development of electric vehicles in China, and then integrated to arrive at a complete morphological matrix analysis framework of electric vehicle operation mode as shown below (Figure 1).

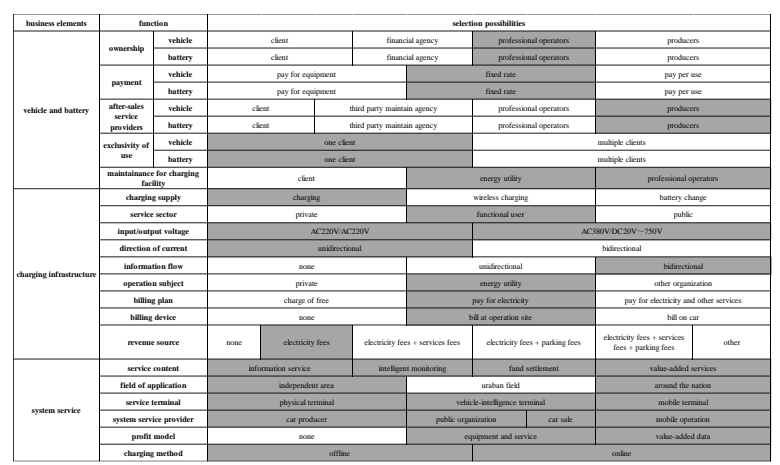

Figure 1 Morphological matrix analysis framework for electric vehicle operating models in china

As can be seen, each element of each module has different characteristics and selection possibilities and can be combined with each other to form a variety of different operating models. The elements of each part will be explained below and analysed through case studies in the following sections.

\section{CASE STUDY OF ELECTRIC TAXI OPERATION MODEL IN BEIJING}

In terms of value creation, the business model c Beijing's taxi operation model adopts the "company contracting + regional operation" model, and the operation model of taxi operation is basically the same in all regions. Therefore, in this paper, we will take Changping District as an example to analyse the commercial operation model of electric taxis in Beijing in depth. Since the demonstration operation in September 2012, electric taxis in Changping District have continued to develop and grow, showing good demonstration effects and operational effects, from the selection of complete vehicles, charging infrastructure construction and system service investment.

As shown in Figure 2, it is a stakeholder diagram of the electric taxi operation model in Changping District. As can be seen in the diagram, with the operator, Beijing Hongdaxing Regional Electric Minibus Limited Liability Company, as the core, the operating company is jointly invested and constructed by the investor (Beijing Hongdaxing Investment Management 
Company), the charging infrastructure operator (State Grid Beijing Electric Power) and the vehicle manufacturer (Foton and BAIC New Energy). It is also financially subsidised by the Beijing Municipal Government and the Changping District Finance Bureau. In addition, operators and car manufacturers, charging infrastructure operators and system service providers all coordinate with each other to enable better access to commercial operations, charging services and smart services for electric taxis.

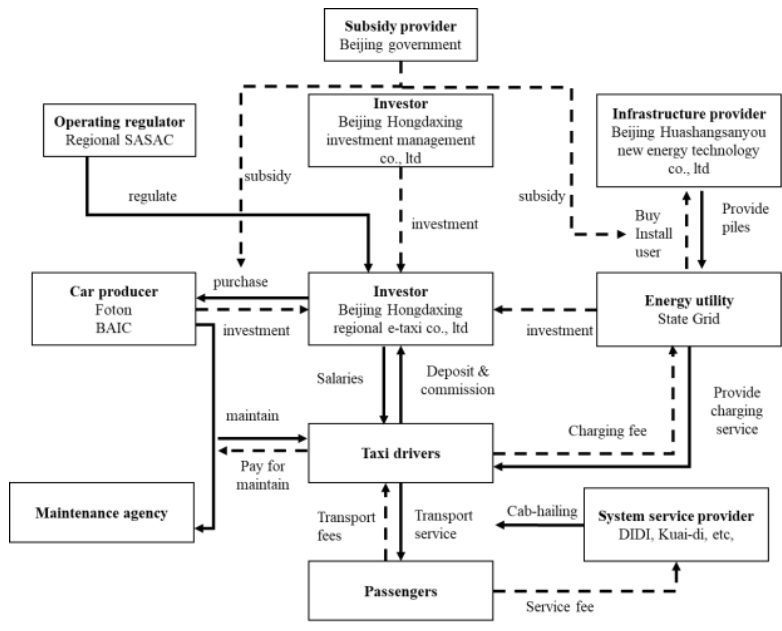

Figure 2 Beijing electric taxi operating model map

The following will be a case study of Beijing's electric taxi operation model through three aspects: the vehicle and battery, charging infrastructure, and system services.

\subsection{Vehicle and Battery}

The relationship between the stakeholders in the taxis in Changping District at the vehicle and battery levels is centred on the operator, Beijing Hongdaxing Regional Electric Minibus Co. New Energy), which is also financially subsidised by the Beijing Municipal Government and the Changping District Finance Bureau.

The morphological matrix gives a clear picture of the operation of the whole vehicle and battery of the electric taxi in Beijing. The grey part of the table shows all the possibilities that are currently in line with the design of the elements of the taxi operation model in Beijing. The taxi body and battery are owned by a professional operator, who acquires ownership of the taxi through the purchase of the vehicle. The main user payer is the taxi driver, who pays a monthly fee to the operator, while the passenger pays the taxi driver on a per-ride basis. At present, the maintenance and aftersales service of electric taxis in Beijing is mainly the responsibility of the manufacturers of the cars and batteries. In terms of construction and maintenance of charging facilities, they are mainly funded by the State
Grid Beijing Electric Power Company, while some charging stations are also invested by Beijing Huashang Sangyou New Energy Technology Co.

The characteristics of the operation mode of the whole vehicle and battery of electric taxis in Beijing are summarised as follows.

(1) On the whole, the morphological framework of the elements of the operation mode of the whole vehicle and battery of Beijing's electric taxis is relatively fragmented, with a bias towards the right-hand side service oriented in terms of vehicle and battery ownership and after-sales service providers, and a lefthand side in terms of exclusivity of use, which can only be used by one customer and is product-oriented.

(2) Ownership of vehicles by professional operators can reduce the burden on drivers, subject to the higher cost of core components such as batteries and the higher purchase cost of electric vehicles. The current purchase price of the Beiqi New Energy EV200 is 226,900. Now professional operators buy the vehicles and receive government subsidies to promote the use of electric taxis, with the price of the BAIC EV200 being around 136,900 after subsidies. It is also more convenient to have a dedicated operator for the daily management and dispatch of taxis.

(3) Taxis are mainly serviced by the car and battery manufacturers, and in the event of a major battery failure, the driver does not have to pay for the repair, the car manufacturer is responsible for the repair. As the car manufacturer directly faces the customer for repairs, and because of the high technical content of electric vehicles, repairs by the car and battery manufacturers are conducive to better maintenance.

(4) Compared to traditional taxis, the short range of electric taxis is a major issue that needs to be considered, and the quality and longevity of the batteries are also a major challenge for operators to invest in and consider.

\subsection{Charging Infrastructure}

All pure electric taxis in Beijing use charging to replenish their power, and the operators of the charging infrastructure are the State Grid and the manufacturers are Beijing Huashang Sangyou New Energy Technology Co. The AC charging piles in each charging station have two charging interfaces, $\mathrm{A}$ and $\mathrm{B}$, with input voltage of $\mathrm{AC} 220 \mathrm{v}$ and current of $11-12 \mathrm{~A}$; the input voltage of $\mathrm{DC}$ charger is $\mathrm{AC} 380 \mathrm{~V} \pm 15 \%$; the mobile fast charging station has five fast charging interfaces with input voltage of $380 \mathrm{v}$ and current of 50A. It takes about $1 \mathrm{~h}$ to fully charge a vehicle using a DC charger. Electric vehicle operators are uniformly equipped with the State Grid's electricity card for 
drivers, who charge their own fees and use the charging facilities at the sites for charging on their own.

Except for Changping and Yanqing, where the electric taxi operators stipulate that electric taxis can only be charged and recharged at the stations, electric taxis in other areas can be recharged at charging points outside the stations. For example, electric taxis in Shunyi District are required to pay a parking fee of RMB 2 per hour when charging at the charging point in the car park of the State Grid Fengbo Subway Station. A State Grid maintenance point located at the charging station site is responsible for monitoring and maintaining the operation of the charging facilities.

From the charging infrastructure operation model in the morphological framework, it is clear that Beijing pure electric taxis use wired charging to supplement the electricity; the input/output voltage is AC220V/AC220V when using AC charging piles, and AC380V/DC20V to $750 \mathrm{~V}$ when using DC chargers or mobile fast charging stations; when the driver is charging at the station, the charging When the driver is charging at the station, the operating body of the charging infrastructure is the national grid, and when it is replenished outside the station, the charging infrastructure used belongs to the social public domain, so the income source of the operator is the electricity fee.

\subsection{System Services}

Based on the above analysis of the content related to system services between different processes in the electric taxi sector, it can be seen that

(1) System service content. The content of system services in the field of electric taxis in Beijing mainly includes information services, intelligent monitoring, capital settlement and value-added services. Information services include the collection and analysis of electric taxi drivers' vehicle operation data by the electric taxi operator; the display of vehicle mileage and power information by the BAIC manufacturer's on-board intelligent display; the display of charging current, charging voltage, charging power and charging time by the intelligent display of the intelligent charging pile; and the provision of taxi driver information and order hailing information by the taxi hailing software. Intelligent monitoring includes the GPS positioning monitoring system of taxi operators for electric taxi vehicles, which facilitates real-time control of the vehicles; the smart grid for monitoring the operation of the charging infrastructure, etc. Financial settlement mainly includes the taxi driver's share fee payment to the taxi operator, the electricity payment to the grid and the intelligent settlement with taxi passengers.

(2) Scope of application. The operation mode of electric taxis in Beijing is regional. Electric taxis can only be operated within the prescribed county area and cannot go beyond the boundaries. For internet companies, the services provided by Drip Fast to taxi drivers and taxi passengers are national in scope, and Drip Fast's business covers the whole country.

(3) Service terminals. The application platform of Beijing's electric taxi system services includes, in addition to traditional physical services, intelligent services through mobile phone APPs, WeChat platforms and other internet media, in addition to the equipment of on-board intelligent systems, such as intelligent displays and intelligent meters.

(4) System service providers. In the operation mode of system services in the field of electric taxis in Beijing, the system service providers are different for each process, and the intelligent system services are carried out by the leading party of each process, while as a whole, the system service providers are mainly provided by the State Grid, taxi operators, electric taxi manufacturers and third-party Internet operators.

(5) Profitability. The profitability of system services is mainly reflected by service equipment fees and service charges. And during the application of the DDT Express software, the data value-added fee is also part of its profit source.

(6) Charging media. Share fee payment and electricity bill recharge are traditional down-line payment methods, while electricity card settlement and Alipay payment and WeChat payment included in the charging methods of the Internet application software are online payment methods.

\subsection{Integration Analysis}

Through the analysis of the morphological matrix of the operation mode of electric taxis in Beijing and nine suburban counties in terms of the whole vehicle and battery, charging infrastructure and system services, combined with actual research, this paper summarizes the characteristics of the operation mode of electric taxis in Beijing.

(1) The "company contracting + regional operation" model compensates for the disadvantage of insufficient range. Due to the wide area of Beijing's urban and suburban areas, a regional operation model has been adopted, making each region a self-contained system that controls taxis within the region.

(2) Basically dominated by BAIC and taxi operating companies, the procurement, maintenance and charging services are more convenient. From the morphological matrix, the operation model of electric taxis in Beijing is relatively uniform across all regions. Although each region is contracted by a company, it is basically operated by BAIC in cooperation with taxi operating companies in the region, and the operation model is 
basically in the form of a financial lease. The advantage of this is that unified procurement and repair and maintenance are more convenient.

(3) The system is richer in services, covering information services, intelligent monitoring, capital settlement and other value-added services, and various terminals and payment methods are provided by various service providers.

\section{PROBLEMS WITH THE OPERATION MODE OF ELECTRIC TAXIS IN BEIJING}

In the process of development there are also many problems.

(1) Large acquisition and operating costs, greater reliance on policy subsidies and, in particular, a strong reliance on core stakeholders to maintain commercial operations. Due to the high cost of vehicle purchase, operators expect more government subsidy policies. In the case of the EV200, for example, the differential subsidy plus the state subsidy and Beijing subsidies already in place would bring the total subsidy on an electric vehicle to $\$ 110,000-120,000$, and if all fuel taxis were replaced through this incentive, government subsidies would reach over $\$ 7$ billion, which is clearly unrealistic. Therefore, under the current operating model, operators will face greater problems in maintaining their capital chains, relying mainly on BAIC and taxi operators in the region to maintain them.

(2) The overall operating model has a single profit model, especially the charging infrastructure module, which is more traditional and has a single profit model. There are also some problems with the current operating model of electric taxis in terms of charging. "Slow charging is a pose, fast charging is not enough", which is a consistent phenomenon in the far suburbs of Beijing at present. Of course, in May 2016, Beijing's electric taxis newly launched a power exchange model, which can solve the driver's charging problem within 3 minutes, making taxi drivers see hope, but it is not yet vigorously promoted for use.

(3) The support in terms of charging infrastructure is not perfect. Many drivers respond that there is not even necessary charging infrastructure such as toilets around the charging stations, and those personal problems such as eating and resting cannot be solved during charging, especially for taxi drivers who carry out slow charging.

(4) The internet factor in the electric taxi sector is limited to the electric taxi driver and passenger, and is taken to be more general technical support, lacking yet a more intelligent and diverse system service. In addition, with the market-oriented development of the electric vehicle operation mode, the system service operation mode will involve more energy suppliers, financial institutions, IT technology enterprises, etc., and the system service providers will also show diversified development.

\section{CONCLUSION}

This paper firstly compares the current situation of the promotion and application of electric taxis and the current situation of the operation model in China, and focuses on the current situation of the promotion of electric taxis in Beijing; on this basis, it combines theoretical research and industrial practice, draws on previous research, constructs a morphological matrix analysis framework of the operation model of electric vehicles in China, and interprets the elements of the operation model in three aspects: the vehicle and battery, the charging infrastructure, and the system service. The theoretical framework is then applied to the case of Beijing's electric taxis, and the various elements and problems of Beijing's electric taxi operation model are analysed.

From the study, it can be seen that the "company contracting + regional operation" operation model adopted by Beijing's electric taxi operation model is currently operating successfully, with a total of 2,650 electric taxis in operation in all districts and counties. In addition, technical support-based system services have also facilitated the operation model.

Of course, Beijing's electric taxi operation model still suffers from inadequate charging infrastructure, a single overall profit model, a lack of diversity and intelligence in system services, and a reliance on subsidies. These are all reflected in the elements of the morphological matrix. Firstly, the operating model has less coverage of the elements of the charging infrastructure module, and more elements need to be added or more favourable elements need to be selected to break through the traditional operating model; secondly, from the perspective of the operating companies, the overall profit model is relatively single and more inclined to the traditional taxi operating model. Thirdly, system services should not be limited to the existing framework, but should break through the general services such as technical support and provide more high-end intelligent and diversified services; in addition, with the policy of subsidy withdrawal, it is more important to seek changes in the operation model, not only to reorganise and filter the elements within the framework of the existing morphological matrix, but also to break through the existing framework of elements In addition, with the withdrawal of subsidies from the policy, it is more important to seek changes in the operating model, not only by reorganising and selecting elements within the framework of the existing morphological matrix, but also by breaking away from the existing elemental framework and expanding the 
types of elements and their possible options, so as to bring more possibilities for operating model innovation.

\section{ACKNOWLEDGMENTS}

This research was supported by SGCC Technology Project (1400-202157208A-0-0-00) - Study on key technologies of Energy Internet industry system coordination and emerging business development.

\section{REFERENCES}

[1] Chu Y., Weng X., (2014). Research on the business model of electric vehicle microbus--Hangzhou City as an example. Journal of Zhejiang University of Technology (Social Science Edition), (03):339-344.

[2] Wang S., (2013). Research on the business model of new energy vehicle promotion. Economic system reform, (3): 101-104.

[3] Ye Q., (2013). Suggestions for market cultivation and business model innovation of electric vehicles in Beijing. Automotive Industry Research, (4): 1620.

[4] Li X., (2013). Research on the business model of electric vehicle operation in China. Business Herald, (7): 133-133.

[5] Liu J., (2016). Wang Peng, Miao Guangyan. Research on the business model of electric vehicle charging industry based on "Internet+". Enterprise economy, (04):148-152.

[6] Miao K., (2016). Research on the innovation of electric vehicle infrastructure business model in Beijing. Beijing Jiaotong University.

[7] Liu Y., Wang J., Kokko A., (2014). Policy and business model innovation of electric vehicle demonstration operation: global experience and Chinese practice. China Soft Science, (12):1-16.

[8] Chen R., Liu X., (2013). Analysis of electric vehicle charging and switching mode. Automotive and Accessories, (50): 36-39.

[9] Yue S., Li Y., (2012). Analysis of electric vehicle charging modes and methods. Communication power technology, 29(2): 38-40.

[10] Vatne A, Molinas M, Foosnas J A., (2012). Analysis of a scenario of large scale adoption of electrical vehicles in nord-trøndelag. Energy Procedia, 20: 291-300.

[11]San Román T G, Momber I, Abbad M R, et al., (2011). Regulatory framework and business models for charging plug-in electric vehicles: Infrastructure, agents, and commercial relationships. Energy policy, 39(10): 6360-6375.

[12] Wang M., (2016). Innovation of electric vehicle system service business model in Beijing. Beijing Jiaotong University.

[13] Wang M., (2013). Feasibility study on the promotion of pure electric vehicle sharing. Traffic and Transportation, 29(H07): 145-147.

[14]Li B., Jiang Y., Cui Y., (2014). Analysis and research on the business model of connected vehicle. Software Industry and Engineering, (1): 31-34.

[15] Ye Q., Wang H., (2012). Theoretical considerations on the business model system of electric vehicles China Science and Technology Forum, (01):44-48.

[16]Kley F., Lerch C., Dallinger D., (2011). New business models for electric cars-A holistic approach. Energy Policy, 39(6): 3392-3403. 